in a single agency with the understanding that regional authorities have acquired of purchasers. The effect would be to create lean authorities, quite unlike the existing ones. Consistent with the spirit of the NHS reforms, as many functions as possible would be devolved or contracted out, enabling regional authorities to focus on their essential tasks.

Which of these options is adopted depends as much on politics and power as on logic and reason. On the one hand, many NHS trusts are likely to resist suggestions they should be brought back under the control of regional health authorities, even if these are radically reshaped. On the other hand, the regional health authorities (including regional chairmen) are certain to want to preserve a role for themselves in future. The views of ministers will therefore be particularly important.

Much hinges on whether ministers believe that it would be helpful to continue to have regional chairmen and nonexecutive members in place. Norman Fowler, when secretary of state for health social services, argued that meetings of regional chairmen acted as a health cabinet in which he could set directions for the NHS, explain the thinking behind government policies, and seek the view of the chairmen. If regional authorities did not exist this means of communication would be cut off and responsibility for implementing policies would rest entirely with managers. Although this would be consistent with the rise of managerialism in the past decade, it would deprive ministers of an independent channel of influence - and a political buffer. The removal of authorities at a regional level would also reduce the already limited participation of lay people in the running of the NHS.

Set against these factors, it can be argued that replacing regional health authorities by outposts of the management executive would have the effect of bringing into existence the clear chain of command heralded in Working For Patients. This would also formally recognise what has been happening over the past few years: regional health authorities have become de facto regional offices of the management executive, so tightly have their activities been controlled from the centre.

The main danger is of a messy compromise. The new ministerial team may instinctively dislike structural change and oppose reorganising the NHS yet again, but this should not prevent it thinking clearly about what arrangements are needed regionally to enable the NHS reforms to work to the best advantage. One way of squaring the circle would be to retain regional authorities but to insist that they adopt a style of working consistent with the new NHS. This option would not only result in a coherent regional approach, it would also force the management executive to review its relationship with regional health authorities to bring this into line with the emphasis on devolved responsibility for management. Whether those at the centre have the inclination to put their own house in order remains to be seen. The worst of all worlds would be to retain two separate regional agencies, neither of which would be capable of providing the overview needed to manage the market properly: it is essential that a single agency is responsible for relating to purchasers and providers.

CHRIS HAM

Professor,

Health Services Management Centre,

University of Birmingham,

Birmingham B15 2RT

\title{
Performance related pay for hospital doctors
}

\author{
So much for sticks, what about some carrots?
}

The General Medical Council's proposed new machinery for dealing with long term poor performance by doctors ${ }^{1}$ will mainly operate retrospectively. It is unlikely to reassure trust managers concerned about risk, who will want to secure better quality in advance. If at the same time they can increase productivity so much better. So it is not surprising to find that performance related pay is already on the agenda, with the doctors' and dentists' pay review body advocating discussion between the professions and the Department of Health, ${ }^{2}$ and the Central Consultants and Specialists Committee indicating its willingness to consider the issues. ${ }^{3}$

Several benefits are claimed for performance related pay. Firstly, it can be used to reward a good contribution (that is, the combined effect of effort and capability). Secondly, it enables managers to send powerful messages to people about whether they want them to stay. Thirdly, it forces managers to evaluate their staff. Perhaps, most importantly, it is said to motivate people to perform better. ${ }^{+}$Unfortunately, doubts exist about whether performance related pay delivers these benefits in practice ${ }^{5}$ and, in the short term at least, it is said to add to wage bills as benevolent managers class all their ducks as swans. ${ }^{6}$ But performance related pay is widespread in the private sector, and such doubts are unlikely to deter those anxious to experiment.

The real difficulties arise when considering how to measure performance. Essentially there are two measurements: inputs and outputs. Performance related pay based on outputs, such as piecework in factories or commission for sales staff, requires repetitive and homogeneous processes. The specialties most suited are surgery, anaesthesia, and diagnostic radiology. But even if reliable indices of output could be developed and agreed between managers and doctors, there would still be several reasons for caution.

These specialties have the highest earners from private practice, with the average practitioner more than doubling his or her NHS salary. ${ }^{7}$ The incentives would need to be sufficiently high to compete for their time, and the additional costs may well exceed any advantages from increased productivity. Complaints about shortages of other vital inputs, such as theatre time, would have added verve when voiced by surgeons whose income was directly threatened. Add to this the possible damage to quality of raising productivity (as in the British car industry in the 1960s) and conflict among practitioners fighting for a share of a limited pool of incentive money, and it is easy to see why even the most ardent proponent of performance related pay might hesitate.

If systems based on output are unattractive what about basing payments on individual input? This has the advantage that all specialists, not only surgeons and anaesthetists, may be included. But most professionals will agree to have their work judged only by peers; accurately assessing input in many medical jobs is fraught with difficulties.

Could the distinction award system be reformed to satisfy the strongest supporters of performance related pay (such as some trust managers) while retaining the support of the profession? There is already a consensus that the process 
should be more open. ${ }^{8}$ But most managers would want new and explicit criteria, with more emphasis on efficiency and productivity and less on academic or medicopolitical merit. Furthermore, they would expect to have a greater hand in setting the criteria and in the review procedure. The payments would almost certainly have to be one off, with no expectation of renewal, thereby raising serious questions about the costs of administering the system. Forward thinking managers may also be considering the merits of rewarding teams instead of individual doctors and including other professionals in the teams. Where teams are stable this is feasible; where team members work for several different teams administration would be difficult. Finally, the reward offered need not necessarily be money: time off in lieu might be an attractive alternative, especially where staff can earn at far higher rates outside the NHS. Is such major reform feasible or will a separate system of performance related pay be necessary (instead of or as well as distinction awards)? The debate is about to begin.

Recognising and rewarding differences in contribution, where they can be fairly shown, has much to recommend it.
But where there is doubt about the fairness, performance related pay may be divisive and demotivating. Even if it is demonstrably fair, it requires considerable skill to evaluate performance accurately, courage to advise poor performers that they will be penalised, and experience to advise them how to improve poor performance. Unless such conditions can be met performance related pay for doctors may be an expensive and unproductive mistake.

Hanwell

Oxfordshire OX17 1HN

Assistant Professor of Organisational Behaviour London Business School

London NW1 4SA

1 Smith R. The GMC on performance. BMF 1992;304:1257-8.

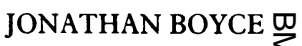

2 Review Body on Doctors' and Dentists' Remuneration. 22nd report. London: HMSO, 1992 (Cmnd 1813.)

3 Central Consultants and Specialists Committee. Annual Report 1992. London: BMA, 1992.

4 Kanter RM. When giants learn to dance. London: Unwin, 1989.

5 Lawler E. Pay and organization development. London: Addision Wesley, 1981.

6 Performance pay. Economist 1992;322:26-31.

7 King's Fund. Going private. London: King's Fund, 1992. (London initiative working paper No 4.)

8 Beecham L. Opening up merit awards. BMF 1992;304:1653.

\section{Campylobacter: epidemiological paradoxes}

\section{The vehicles for most cases of infection remain unknown}

Campylobacter has been the commonest reported bacterial cause of diarrhoea in Britain since $1981 .^{1}$ Campylobacter jejuni has been estimated to account for over $95 \%$ of human campylobacter infections in England and $C$ coli for nearly $5 \%$. $^{2}$ These two species share many clinical and epidemiological characteristics.

The Public Health Laboratory Service Communicable Disease Surveillance Centre first recorded cases of campylobacter infection in 1977 after Skirrow's description of a selective stool culture medium for $C$ jejuni. ${ }^{3}$ The numbers of cases reported rose every year to reach over 34500 in 1990 but fell in 1991 to about $32600 .{ }^{4}$ About $10 \%$ of people found to be infected have acquired the infection abroad. The early rise in reports throughout the 1980 s probably resulted from more frequent identification rather than a true increase in incidence. Nevertheless, campylobacter infection is undoubtedly an important public health problem in Britain and elsewhere.

Fewer than 10 deaths in people with campylobacter infection have been reported in England and Wales since 1981 (Public Health Laboratory Service, Communicable Disease Surveillance Centre, unpublished data), and most of these were in patients with predisposing conditions; but the disease causes considerable morbidity and may occasionally have serious sequelae, including the Guillain-Barré syndrome. ${ }^{6}$ Campylobacter infection is also expensive. A study in 1986 estimated that each identified case in England cost $£ 587-\mathbf{a}$ total of $£ 14$ million in that year. ${ }^{7}$ Not all cases are identified, so the total cost to the community is probably much greater.

Campylobacters are common in sewage and have been cultured from untreated water. ${ }^{8}$ They are found frequently in the intestines of animals of many species; on raw meats, especially poultry meat ${ }^{9}$; and in raw milk. ${ }^{10}$ Despite its widespread distribution the organism does not multiply below $30^{\circ} \mathrm{C}^{11}$ and is therefore unlikely to grow on food at room temperature.

Many vehicles of infection have been identified in outbreaks, both from epidemiological and microbiological evidence. These include untreated water ${ }^{12}$ and water from storage tanks, which may have been contaminated after $\vec{\oplus}$ treatment ${ }^{13}$; raw milk ${ }^{10}$ and milk that may have been inadequately pasteurised ${ }^{14}$; and undercooked meats, including poultry meat. ${ }^{15}$ Cross contamination also occurs, allowing foods as diverse as salads and cake icing to be vehicles. ${ }^{16}$ Asymptomatic excretion of campylobacter is unusual, ${ }^{17}$ and infected food handlers do not seem to present a risk.

Indeed an odd feature of campylobacter diarrhoea is that $\overrightarrow{\overrightarrow{0}}$ although isolated cases are common, outbreaks are rarely 3 reported. Fewer than $1 \%$ of the cases reported to the Communicable Disease Surveillance Centre in 1991 were part of known outbreaks. Furthermore, even though some causes of outbreaks have been shown to be responsible for some? sporadic infections as well - for example, consumption of raw milk $^{18}$ and undercooked chicken ${ }^{19}$ and handling of raw. chicken $^{20}$-the vehicles are not necessarily the same. Other risk factors more specific to sporadic infections have been identified and include contact with pets, particularly puppies with diarrhoea, ${ }^{21}$ and, in some parts of Britain in the spring, $\mathscr{N}$ drinking milk that has been delivered to the door and has beeno pecked by birds such as magpies and jackdaws. ${ }^{22}$ This last finding may explain, at least partially, why reports rise in the spring-one of the enigmas of campylobacter infection. It ${ }^{\omega}$ does not, however, explain the autumn rise. Nor is there any? known explanation for most of the cases which occur? throughout the year.

Person to person spread seems to be unusual. Familyo clusters are seldom seen, and secondary transmission aftero. point source outbreaks is also rare. This is puzzling-the@ infective dose may be as small as 500 organisms, ${ }^{23}$ and $\mathbb{Q}$ diarrhoeic faeces can contain as many as $10^{6}-10^{9}$ organisms per gram. ${ }^{24}$

Why, then, are outbreaks, clusters, and secondary infect tions so infrequent, and what are the routes of infection in theo many patients who do not seem to have been exposed to known risk factors? The first question may be answered by the widespread existence of immunity in the population resulting from repeated exposure to the organism. There is 